\title{
Resenha
}

\section{A Democracia Radical e Plural: um projeto político para a esquerda}

\author{
Radical and Plural Democracy: \\ a political project to the left
}

\author{
Kamila Lima do Nascimento \\ Doutoranda em Ciência Política, Universidade Federal de Pelotas, \\ Pelotas, RS, Brasil \\ kamiladonascimento@gmail.com
}

\begin{abstract}
Resumo: Este artigo tem por objeto apresentar a noção de Democracia Radical e Plural promovida pelos teóricos políticos Ernesto Laclau e Chantal Mouffe. O trabalho de ambos os autores vem ganhando destaque no campo das discussões da ciência política e motivado a construção de diversos conceitos que tomam por base a radicalidade e a pluralidade imbuídas em seu projeto teórico. No Brasil, os autores são ainda pouco conhecidos e sua obra, extensa e densa, muitas vezes dificulta sua inclusão nas agendas de pesquisa. A Democracia Radical e Plural não é um projeto normativo stricto senso, mas um constructo inabacado e um porvir. Por isso mesmo, sua utilização sem as devidas precauções pode levar a mal entendidos. Ela é uma contribuição que os autores oferecem à esquerda política e que se constitui numa série de sugestões a partir dos quais um projeto democrático de esquerda poderia ser desenvolvido em oposição aos demais projetos democráticos atualmente existentes. Nosso trabalho visa colaborar para esclarecer e divulgar esta noção, ainda pouco trabalhada em língua portuguesa e contribuir para as pesquisas elaboradas por outros pesquisadores a partir dela, pois acreditamos que sua compreensão adequada é central para sua utilização no campo de pesquisa.
\end{abstract}

Palavras-chave: Democracia Radical e Plural; Ernesto Laclau; Chantal Mouffe.

\footnotetext{
Abstract: This article's purpose is to present the notion of Radical and Plural Democracy promoted by political theorists Ernesto Laclau and Chantal Mouffe. The work of both authors is gaining prominence in the field of political science discussions and motivated the construction of various concepts that are based on the radicalism and the plurality imbued in its theoretical design. In Brazil, the authors are still little known and his and her work, extensive and dense, often makes difficult their inclusion in research agendas. Radical and Plural Democracy is not a normative project strict sense but rather a future construct. Therefore, its use without proper
} 
precautions can lead to misunderstandings. It is a contribution that the authors offers to the political left and that is a series of suggestions from which a democratic project of left could be developed as opposed to other currently existing democratic projects. Our work aims to contribute to clarify and disseminate this notion, little worked in Portuguese language and contribute to research compiled by other researchers from it, as we believe that a proper understanding is central to its use in the search field.

Keywords: Radical Democracy and Plural; Ernesto Laclau; Chantal Mouffe.

\section{Introdução}

O problema da democracia é tão antigo quanto à reflexão sobre as coisas da política, tendo sido (re)proposto e reformulado em diversos momentos e lugares (BOBBIO; MATTEUCCI; PASQUINO, 1998). O cenário atual não é diferente e o debate em torno da questão democrática parece estar longe de chegar ao fim. Nosso trabalho intenta ser mais uma contribuição para esta discussão através da apresentação da noção de Democracia Radical e Plural nas obras dos teóricos Ernesto Laclau e Chantal Mouffe.

Os autores que pertenceram à escola marxista até meados dos anos 80, propuseram uma virada teórica a partir de 1985 com a publicação da obra Hegemonia e Estratégia Socialista onde também apresentaram pela primeira vez a noção de democracia radical e plural que aperfeiçoariam ao longo de suas obras. Parecia natural que eles enquanto pós-marxistas' seguissem em seu projeto político o modelo revolucionário socialista, mas ao contrário, eles fizeram duras críticas ao projeto marxista e posicionaram-se inteiramente na luta pela democracia. Os autores partiam da ideia de que a tarefa da esquerda não poderia ser "[...] renunciar à ideologia liberal-democrática, mas, ao contrário, aprofundá-la expandi-la na direção de uma democracia radicale plural."2 (LACLAU; MOUFFE; 2015, p. 264). Por outro lado, eles defendiam que o projeto socialista ainda tinha muito a colaborar para a criação de um projeto democrático, desde que seus pressupostos fossem reformulados.

Para apresentar a noção dos autores nós dividimos o trabalho em três partes. Na primeira parte, nós trataremos de apresentar o conjunto geral de ideias que compõem o imaginário democrático de onde Laclau e Mouffe partem para desenvolver sua democracia radical e plural, marcando deste modo à diferença entre a teoria geral da democracia e suas

1 Pós-marxismo é uma referencia que significa ir além da teoria marxista, mas sem rejeitá-la completamente.

2 Este posicionamento foi radicalizado pelos autores em obras posteriores, onde criticaram mais duramente o projeto liberal, mas sem nunca rejeitar completamente seus esforços. 
formas normativas e contingentes. Na segunda parte, nós mostraremos os dois projetos políticos que influenciaram a construção da noção de democracia radical e plural, quais sejam: a democracia liberal e socialismo. Por fim, mostraremos, na terceira seção, os elementos constitutivos e as especificidades do projeto de democracia radical e plural ao longo das obras de Ernesto Laclau e Chantal Mouffe.

\section{O imaginário democrático}

Nesta primeira seção trataremos de apresentar o conjunto geral de ideias que compõem o imaginário democrático de onde Laclau e Mouffe partem para desenvolver sua democracia radical e plural. Há duas razões fundamentais que justificam esta apresentação prévia. Em primeiro lugar, para demarcar claramente o que não compõe a especificidade da noção dos autores, mas pertence a uma teoria geral de democracia. Em segundo lugar, porque essa mesma diferenciação também nos ajudará a separar esta mesma teoria geral de democracia do modelo normativo mais comumente ligado a ela, a democracia representativa liberal. Essa separação é importante para mostrar que esta última não é o modelo democrático natural, mas o resultado de um trabalho hegemônico que os teóricos mencionados visam contestar.

De acordo com Laclau e Mouffe (2015), o imaginário democrático moderno começou a ser delineado a partir da Revolução Francesa, com primeira experiência de democracia baseada unicamente na legitimidade do povo e que substituiu a divisão social hierárquica e desigual, pelos princípios democráticos da liberdade e da igualdade. Ao criar uma sociedade horizontal em que todos os homens são iguais e livres a Revolução mudou o imaginário social criando uma "[...] pátria intelectual comum da qual os homens de todas as nações podiam tornar-se cidadãos." (TOCQUEVILLE, 1997, p. 59). Em meio ao caos revolucionário, o rei é destronado dando lugar à revolução democrática ${ }^{3}$ e a disputa pela ocupação provisória do poder e a soberania é transferida deste para o povo, proclamado como portador e, ao mesmo tempo, realizador dos princípios da revolução.

Para marcar a diferença radical deste novo regime é preciso destacar que a França pré-revolução era governada por uma monarquia em que o poder central e absoluto estava nas mãos do rei que governava como representante de Deus. Era a partir dele e

3 Laclau toma a expressão de empréstimo de Tocqueville. 
de suas vontades que o direito e a justiça eram distribuídos para o resto do corpo social de forma vertical e hierarquizada. Tratava-se de uma sociedade de súditos, pautada no privilégio que somente o monarca poderia distribuir, e cujo poder estava ocupado por toda a eternidade (FURET, 1989).

A democracia, ao contrário,

[...] é institucionalizada e sustentada pela dissolução dos marcadores da certeza. Ela inaugura uma história na qual o povo vivencia uma indeterminação fundamental no que se refere à base do poder, à lei e ao conhecimento. (LACLAU, 2013, p. 240).

No regime anterior o rei era a fonte original e imutável de todo poder, não havendo qualquer espaço para indeterminação,

[...] a transição para [a] nova situação [é] caracterizada pela instabilidade essencial dos espaços políticos, na qual a própria identidade das forças em conflito é submetida a constantes mudanças, exigindo um incessante processo de redefinição. (LACLAU; MOUFFE, 2015, p. 233).

Quanto a isso há duas coisas importantes a reter. Em primeiro lugar, os princípios da lógica democrática alteraram o critério de pertencimento social. Num sistema de estamentos como aquele anterior à Revolução, o critério é hierarquizado e desigual e, consequentemente, as relações sociais tomam esta forma desigual. Uma vez que o critério é alterado para o da igualdade, a desigualdade social passa a ser vista como uma anomalia e torna-se um problema a ser combatido.

Em segundo lugar, a forma de resolução dos problemas sociais passa a ser o da disputa política. Não havendo mais um centro, o poder começou a ser ele mesmo pauta de disputa. Os princípios da igualdade e da liberdade tornaram possível a politização de problemas antes considerados da esfera privada.

A partir daí, a linha demarcatória entre o interno e o externo, [público e o privado] [...] tornou-se cada vez mais frágil e ambígua, e sua construção tornou-se o problema crucial da política. Quer dizer, a partir de então não houve mais política sem hegemonia. (LACLAU; MOUFFE, 2015, p. 234).

Laclau e Mouffe exemplificam o efeito subversivo da revolução democrática através da distinção entre relações de subordinação e relações de opressão. Relações de subordinação são aquelas em que "[...] um agente é sujeito às decisões de outrem - um empregado 
face a um patrão, por exemplo, ou, em certas formas de organização familiar, a mulher face ao homem, e assim por diante." (LACLAU; MOUFFE, 2015, p. 236). Nesse caso, trata-se de uma desigualdade socialmente aceita. Já uma relação de opressão acontece quando uma relação de subordinação torna-se um ponto de antagonismo, ou seja, quando ele ocorre à revelia da vontade e dos direitos do oprimido.

Ao colocar todos os homens em posição de simetria, o princípio da igualdade criou numerosos novos pontos de antagonismo no social, redefinindo relações de subordinação em relações de opressão, já que não havia mais sentido falar em diferenças hierárquicas "naturais".

Aqui está o poder profundamente subversivo do discurso democrático, que permitiria a expansão da igualdade e da liberdade para domínios cada vez mais vastos, e atuaria como elemento de fermentação sobre diferentes formas de luta contra a subordinação. (LACLAU; MOUFFE, 2015, p. 239).

A partir daí tem-se a possibilidade de multiplicar as pautas, os espaços assim como se multiplicam as identidades sociais. Antes disso,

[...] não se falava em "identidade", nem em "reconhecimento" - não porque as pessoas fossem destituídas de (aquilo a que chamamos) identidade, [...] mas, sim, porque, não eram suficientemente problemáticas para serem discutidas como tal. (TAYLOR, 1998, p. 55).

Dessa forma, a lógica política da democracia é responsável por mudar radicalmente o imaginário social, subvertendo as relações anteriormente estruturadas. Contudo a lógica da democracia é incapaz de realizar aquilo que promete. Como meras ideias, "liberdade" e"igualdade" não mudam nada. O discurso democrático não pode exercer este efeito de interrupção sobre relações de subordinação, até que o imaginário democrático torne-se incorporado em normas e instituições (SMITH, 1988, p. 9).

A luta contra a subordinação não pode ser o resultado da própria situação de subordinação. [...] Somente em certos casos essas formas de resistência tomam um caráter político e se tornam lutas dirigidas a pôr fim a relações de subordinação como tais. (LACLAU; MOUFFE, 2015, p. 235). 
Isto acontece, segundo Laclau e Mouffe, porque a lógica política da democracia não possui um conteúdo positivo ${ }^{4}$ ou uma ideia pré-construída a partir do qual o social deveria ser organizado.

Ela é simplesmente o deslocamento ${ }^{5}$ equivalencial do imaginário igualitário para relações sociais cada vez mais abrangentes e, como tal, é apenas uma lógica da eliminação de relações de subordinação. (LACLAU; MOUFFE, 2015, p. 278).

Logo, o que faz a democracia é abrir o leque de possibilidades e institucionalizar o modo como às disputas serão conduzidas. Entretanto, a democracia nega-se a dar a sua própria organização e a seus próprios valores o status de um fundamento. O que faz, ao contrário, é rejeitar toda e qualquer forma de essencialismo, ou seja, que qualquer projeto positivo possa instalar-se finalmente e definir todas as relações sociais.

Há democracia na medida em que existe a possibilidade de questionamento ilimitada, [...] a democracia não é um sistema de valores e um sistema de organização social, mas uma certa inflexão. (LACLAU, 2000, p. 197).

Isso não significa, contudo, que a necessidade de uma organização positiva seja eliminada. Se o imaginário democrático necessita ser incorporado em normas e instituições isso significa que ele necessita ligar-se a algum projeto político normativo que ofereça uma ordem para o social a partir de um conjunto positivo de propostas para a comunidade. Dito de outro modo, a expansão dos efeitos da revolução democrática e a realização de seus princípios dependem diretamente de um projeto positivo em torno do qual a sociedade possa ser organizada.

Aqui fica clara a diferença entre o imaginário democrático e um projeto político democrático. O primeiro constitui-se numa série de princípios básicos que estabelecem a democracia como o governo do povo e que se baseia na igualdade e na liberdade e na negação de uma essência única para o social. Esses princípios inauguram um novo imaginário que, no entanto, para se consolidar precisam ser indexados a um conteúdo normativo positivo. É este conteúdo normativo que um projeto de democracia radical e plural deve oferecer a fim de desafiar o projeto normativo vigente, a democracia

4 Positivo nesse caso pode ser pensado como equivalente a normativo.

5 Deslocamento refere-se a um momento de mudança radical das estruturas sociais em que uma nova forma de organização substitui o anteriormente instituído. 
representativa liberal. Isso significa consequentemente que o imaginário democrático e o modelo representativo liberal também não constituem uma ligação necessária, mas contingente, que foi historicamente construída, como veremos a seguir. Na próxima seção, falaremos das duas grandes lutas políticas originadas na revolução democrática que disputaram a positivação do social pós-deslocamento, a democracia liberal e o socialismo. É a partir de ambos, suas qualidades e problemáticas, que os autores constroem suas sugestões para um projeto político da esquerda e por isso conhecer suas ideias mais centrais é fundamental.

\section{As duas grandes lutas políticas modernas}

Como dissemos na seção anterior, a democracia enquanto lógica política não fornece um conjunto positivo para organização social e seus ideais só podem ser realizados a partir de um projeto positivo que ela mesma não fornece. Durante a revolução democrática moderna, duas grandes lutas emergiram, dois projetos positivos que intentaram parar os efeitos subversivos revolucionários cada um em seu favor e disputaram, e disputam até os dias de hoje, o direcionamento do imaginário democrático. Essas lutas são a da democracia defendida principalmente pelos liberais, e o socialismo, defendido especialmente pelos marxistas. Nesta seção nós falaremos um pouco sobre cada uma dessas lutas para mostrar, por um lado, as críticas de Laclau e Mouffe contra ambas, e, por outro lado, para mostrar as como os ideais de cada uma delas é resgatado e modificado pelos autores em favor de um projeto político para a esquerda.

Comemos pelas críticas de Laclau e Mouffe contra o socialismo clássico representado pelo marxismo. Em primeiro lugar, a ideia da revolução. Esta supunha a extinção de todas as formas de subordinação através do desaparecimento da propriedade privada dos meios de produção. Após um período transitório de ditadura do operariado, seria constituída uma nova sociedade completamente reconciliada em que o antagonismo teria sido extirpado e os homens seriam tão iguais quanto poderiam, sem qualquer divisão social entre eles.

Esta ideia é rejeitada por Laclau e Mouffe. Os autores concordam que, de fato, ".... em muitos casos a derrubada violenta de um regime repressivo é a condição de todo avanço democrático." (LACLAU; MOUFFE, 2015, p. 265). Entretanto, os autores negam a ideia da 
revolução como ato fundacional ou um ponto em que o poder poderia ser abolido e a sociedade racionalmente organizada seria possível.

Há duas razões principais para tanto. Em primeiro lugar porque os autores negam que uma emancipação total seja possível, logo, que uma revolução possa fundar um poder totalmente novo e descolado do anterior, ou extirpar qualquer forma de poder. Aceitar a premissa de que "[...] a luta de classes conduz, necessariamente, à ditadura do proletariado" (MARX, 1975, p. 481) seria o mesmo que aceitar que há apenas uma solução fundamental e, portanto, negar a contingência histórica.

Em segundo lugar porque para eles, nenhuma revolução tem sua direção determinada e deve ser pensada em suas múltiplas possibilidades, pois o deslocamento provocado por ela não possui uma direção pré-determinada. Dessa forma, não seria possível pensar diante mão que o resultado provado seria progressista, nem mesmo favorável à esquerda de modo automático.

Uma segunda crítica de Laclau e Mouffe é contra os pressupostos essencialistas da reflexão de Marx. O problema segundo os autores é que Marx pensou sua teoria num momento em que a divisão do espaço político em termos da dicotomia povo/ ancien regime parecia ter perdido sua potencialidade explicativa no contexto da complexidade das sociedades industriais. Marx procurou recriar tal divisão a partir de um novo princípio: o confronto de classes. Mas, para Laclau e Mouffe, este novo princípio já estava minado desde o início (LACLAU; MOUFFE, 2015).

Isto porque segundo eles, a oposição de classes é incapaz de dividir a totalidade do corpo social em dois campos antagônicos, aos moldes da antiga dicotomia e se reproduzir automaticamente como linha de demarcação na esfera política. De fato, o apriorismo essencialista é para os autores o obstáculo fundamental da esquerda. "A convicção de que o social é suturado em algum ponto, a partir do qual é possível fixar o sentido de todo evento, independentemente de qualquer prática articulatória." (LACLAU; MOUFFE, 2015, p. 264). Isso teria causado uma espécie de cegueira para a real contingência do social limitando a capacidade de ação e análise política da esquerda.

Esta lógica de pontos privilegiados tem operado numa variedade de direções. Do ponto de vista da determinação dos antagonismos fundamentais, o obstáculo básico, como vimos, tem sido o classismo: quer dizer, a idéia de que a classe trabalhadora representa o agente privilegiado em que reside o impulso fundamental de mudança social - sem se perceber 
que a própria orientação da classe trabalhadora depende de um equilíbrio político de forças e da radicalização de uma pluralidade de lutas democráticas que são decididas, em boa parte, fora da classe em si. (LACLAU; MOUFFE, 2015, p. 264).

Um terceiro ponto de crítica de Laclau e Mouffe e que está diretamente ligado ao segundo ponto é quanto à criação de uma identidade de classe universal que se faria as expensas das outras identidades sociais, consideradas secundárias. Para eles, nenhum tipo de projeto deve partir do princípio de que certas identidades devem sacrificar-se em nome de outras. Além do mais, mesmo que uma identidade de classe pudesse ser forjada ela apenas seria fruto da contingência e nunca de uma necessidade. De fato, para Laclau e Mouffe, a complexidade do social mostrou justamente o oposto, que "[...] não existem, por exemplo, vínculos necessários entre antisexismo e anticapitalismo, e uma unidade entre ambos só pode ser resultado de uma articulação hegemônica." (LACLAU; MOUFFE, 2015, p. 266).

Laclau e Mouffe também rejeitam a ideia de que a luta contra o capitalismo seja um ponto privilegiado e que todas as outras lutas apenas sejam parte e consequência desta. Para eles, não há ponto privilegiado de ruptura ou de confluência das lutas sociais, mas pluralidade e indeterminação, e estas devem ser "[...] as duas bases fundamentais a partir das quais um novo imaginário político pode ser construído, radicalmente libertário e infinitamente mais ambicioso em seus objetivos do que o da esquerda clássica." (LACLAU; MOUFFE, 2015, p. 235).

Passemos agora às criticas de Laclau e Mouffe contra os liberais. A primeira que podemos destacar é quanto ao apagamento do antagonismo da política em favor da racionalidade burocrática promovida pelo projeto de democracia liberal. Há, segundo os autores, um movimento generalizado tanto da esquerda quanto da direita em direção ao centro. Tal movimento é considerado um avanço da política, uma espécie de amadurecimento da guerra para a diplomacia, que levaria da disputa irracional a uma racionalidade política superior em que as decisões podem ser tomadas após debate. Para Laclau e Mouffe tal falácia, longe de ser um avanço, implica na tentativa de acabar com a pluralidade política, transformando a disputa em escolha técnica e apagando o conflito de interesses que é próprio da política. (LACLAU; MOUFFE, 2015). 
Para os autores, ao contrário, "[...] uma esfera pública de argumento racional não-excludente é uma impossibilidade conceitual"6 (LACLAU; MOUFFE, 2015, p. 46). Isto porque a única forma de se alcançar tal situação seria através da erradicação de todo antagonismo e de todo poder, que excluiria, por sua vez, todo o conflito do social. A administração social através da negação do conflito "[...] longe de ser a única ordem societal natural ou possível, é a expressão de uma certa configuração de relações de poder." (LACLAU; MOUFFE, 2015, p. 45).

O grande problema é que não é possível estabelecer uma nova hegemonia sem a criação de fronteiras políticas. Consequentemente, aceitar o deslocamento de um terreno ideológico em direção ao centro implica a renúncia de outras alternativas de mudanças sociais que não se adequem ao projeto liberal. Para Laclau e Mouffe, é preciso fazer justamente o contrário, reconhecer que não é possível "[...] haver política radical sem a definição de um adversário. Ou seja, tal política requer a aceitação da inerradicabilidade do antagonismo." (LACLAU; MOUFFE, 2015, p. 45).

A segunda premissa liberal que Laclau e Mouffe intentam romper é aquela ligada ao individualismo burguês. De acordo com ela a sociedade é formada pela a agregação de indivíduos portadores de direitos "naturais". É a ideia de que a sociedade seria fruto de um contrato no qual os indivíduos assinaram a renúncia à parte de seus direitos em nome da proteção do Estado. Para Laclau e Mouffe, essa premissa esconde o fato de que os indivíduos não vivem isoladamente e que, na verdade, participam de relações sociais em um contexto social coletivo. Eles defendem que, ao invés de direitos individuais, devemos pensar, ao contrário, em "direitos democráticos", que possam ser exercidos coletivamente, e que supõem a existência de direitos iguais para outros. Trata-se de "[...] direitos que envolvem outros sujeitos que participam na mesma relação social." (LACLAU; MOUFFE, 2015, p. 274). Os autores ainda defendem que não existe algo que se pudesse chamar de direitos naturais. Todo e qualquer direito é por definição político e, portanto, contingente.

Um terceiro ponto rejeitado pelos autores é quanto à dicotomia entre público e privado. Já falamos um pouco sobre este ponto. Os princípios da igualdade e da liberdade trazidos pela revolução democrática colocaram em pauta pública problemas sociais que antes eram considerados privados. Contudo, uma vez que a revolução é parada

6 No caso específico dessa citação os autores estão criticando a teoria da democracia de Jürgen Habermas. 
e substituída pelo regime democrático liberal, a linha demarcatória entre público e privado foi novamente traçada. Nesta nova demarcação naturalizou-se novamente a divisão fazendo com que sociedade civil e sociedade política fossem separadas, e, logo, que uma série de pautas fossem consideradas naturalmente públicas ou privadas.

O que Laclau e Mouffe salientam quanto a isto é que essa divisão é o resultado de um certo tipo de articulação hegemônica e seus limites variam de acordo com as relações de força existentes num momento dado e não um dado natural. Para eles, ao contrário, a linha entre o público e o privado é móvel, ou seja, pode e deve ser constantemente desafiada, pois não há problemas naturalmente públicos ou privados, mas uma transição de um a outro que é sempre fruto de uma luta hegemônica travada sempre no campo da política. Dito de outro modo, qualquer problema considerado num dado momento como particular pode vir a se tornar, a partir de uma articulação hegemônica, um problema público.

Um quarto ponto de crítica dos autores é quanto à premissa de que a economia pertenceria à esfera do privado. Ora, se dicotomia público-privado é falsa não faz sentido dizer que a economia pertenceria exclusivamente a um ou a outro lado. Trata-se de uma divisão fruto de uma operação hegemônica e não natural e, como tal, pode ser questionada. Dessa forma, os autores trazem o problema da economia e, consequentemente, das desigualdades sociais, para dentro do âmbito publico (LACLAU; MOUFFE, 2015).

Apesar das limitações, cada uma dessas lutas possui também aspectos absolutamente positivos do ponto de vista de Laclau e Mouffe. O liberalismo por ter sido responsável por expandir os regimes democráticos pelo mundo e pela defesa dos direitos das minorias. O socialismo por defender os direitos coletivos e pela tentativa de mudar o social de forma radical. Por essa razão, os autores não as viam como inimigos a serem destruídos, mas como projetos limitados que necessitavam ser revistos. De fato, Laclau e Mouffe acolherem elementos de ambas em seu próprio trabalho. Eles acreditavam que os princípios do liberalismo de defesa das liberdades individuais, por exemplo, deveriam ser expandidos e também que a tradição socialista poderia servir de base para os novos projetos da esquerda, desde que tivesse seus pressupostos questionados. E foi exatamente isso que eles tentaram fazer com sua noção, como veremos a seguir. 


\section{A democracia Radical e Plural}

Na última seção deste artigo, trataremos da noção de democracia radical e plural. Já adiantamos algumas informações que nos fornecem pistas de onde Laclau e Mouffe se movem, resta-nos agora adentrar em suas especificidades para conhecê-la mais profundamente. Antes de tudo, é preciso esclarecer que a democracia radical e plural como desenvolvida pelos autores não é um projeto normativo stricto senso e logo não cumpre a função de oferecer uma proposta final em torno do qual o social poderia ser organizado, como o que dissemos que a lógica política da democracia requer. Ele se constitui como uma série de sugestões a partir dos quais um projeto democrático de esquerda poderia ser desenvolvido em oposição aos demais projetos democráticos que atualmente cumprem essa tarefa. Esta série de sugestões não aparece de modo organizado, mas de forma fragmentária e esparsa ao longo os textos dos autores. Nós, contudo, faremos uma apresentação mais ou menos didática destas sugestões com o intuito de facilitar a compreensão do leitor.

A primeira sugestão de Laclau e Mouffe que podemos mencionar é que para eles um projeto democrático radical e plural deve se fundar na negação da essência do social e na afirmação da contingência como constitutiva deste. Isso significa situar-se no terreno teórico-metodológico pós-estruturalista que pressupõe que o social não possui um fundamento último, mas é constituído apenas por sedimentações parciais e contingentes. Trata-se de negar "[...] as formas originais de pensamento democrático [que] estavam ligada a uma concepção positiva e unificada da natureza humana e, nesta medida, tendiam a constituir um espaço único." (LACLAU; MOUFFE, 2015, p. 269).

A importância deste ponto não deve ser subestimada. Como dissemos há pouco, o imaginário democrático tem como efeito a dissolução dos marcadores de certeza. Quando o rei é destituído, a univocidade do saber e a unidade do poder são substituídas por construções democráticas parciais e provisórias. Além disso, os princípios da igualdade e da liberdade operam diversificando o campo das relações sociais que a partir de então só se tornaram mais complexas. Apesar disso, diante da novidade, as construções teóricas que se desenvolveram em seguida continuaram por se inspirar na teoria da soberania que persistiu como ideologia. Dito de outro modo, a soberania 
foi simplesmente transferida do rei para o povo e as teorias tentaram adaptar a nova situação a partir das referências que já existiam.

Como já citamos, o próprio Marx tentou recriar a divisão do espaço político através da luta de classes. Pelo lado da democracia liberal a permanência da teoria da soberania continuou presente através da permanência das teorias do contrato social, considerando os indivíduos de modo isolados. Nessa esteira o aumento da complexidade das relações sociais foi tomado enquanto diversificação dentro de um espaço único e não como diversidade em um espaço plural. Haveria um universal compartilhado fechado em torno do qual um projeto político poderia se localizar e resolver finalmente todos os problemas políticos. Entretanto, para Laclau e Mouffe, todo projeto político que vise erradicar todo o poder, seja substituindo-o pela racionalização ou seja pela emancipação total do social, não pode ser um projeto plural, visto que nesse caso haveria um só caminho e um só modelo aceitável de sociedade.

De acordo com os autores, essas teorias não dão conta de pensar o espaço político atual e tendem a homogeneizar os indivíduos e excluir a pluralidade. Para eles é preciso, ao contrário, renunciar

[...] à categoria de sujeito como entidade unitária, transparente e suturada [e abrir] caminhos para o reconhecimento dos agonismos constituídos na base de diferentes posições de sujeitos e, logo, para a possibilidade de aprofundamento de uma concepção pluralista e democrática. (MARQUES, 2008, p. 64).

A universalidade característica de uma democracia deve ser pensada como uma universalidade incompleta e é dessa premissa que um projeto radical e plural deve partir. Isso não significa a renuncia da própria ideia de um universal compartilhado, mas a aceitação de que toda ideia universalizada, ou podemos dizer que se hegemonizou, é sempre parcial e precária. “O universalismo não é rejeitado, mas particularizado." (MOUFFE, 1993, p. 13).

A pluralidade característica de um projeto democrático radical não deve ser confundida com diversificação dentro de um espaço unificado. No pluralismo "[...] próprio de uma democracia radical, diversificação se transforma numa diversidade, já que cada um desses elementos e níveis diversos não é mais a expressão de uma totalidade que os transcende." (LACLAU; MOUFFE, 2015, p. 281). Ainda para os autores de hegemonia:

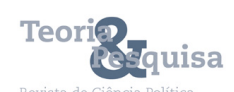


A multiplicação de espaços e a diversificação institucional que a acompanha não mais consistem num desdobramento racional de funções, nem obedecem a uma lógica subterrânea que se constitui no princípio racional de toda mudança, mas exprimem exatamente o contrário: através do caráter irredutível dessa diversidade e pluralidade, a sociedade constrói a imagem e a gestão de sua própria impossibilidade. (LACLAU; MOUFFE, 2015, p. 282).

A segunda sugestão dos autores é de que um projeto político radical e plural deve reconhecer a hegemonia como lógica política legítima de construção das identidades sociais e aceitar um campo de constantes lutas e a possibilidade permanente de contestação da positividade vigente. Reconhecer e aceitar porque para os autores a hegemonia não é um projeto ideal, mas um dado da sociedade democrática moderna e logo, não é negando a hegemonia que a esquerda poder lutar contra a ordem de coisas como estão postas, mas entendendo o seu funcionamento para propor uma contra hegemonia popular.

Como dissemos antes, nenhuma sociedade pode se pautar apenas na fragmentação. É preciso que a diversidade social seja articulada através de uma hegemonia, e, ainda assim, que hegemonia será escolhida não é possível conhecer antecipadamente. A lógica democrática abre caminhos, mas esses caminhos podem ser atravessados "[...] por lógicas políticas tão diversas quanto o populismo e o totalitarismo de direita, por um lado, e uma democracia radical, por outro." (LACLAU; MOUFFE, 2015, p. 254). Entender o caráter "possível" da hegemonia é fundamental por que

[...] implica em que estas novas lutas não têm necessariamente um caráter progressista, e que é, portanto, um erro se pensar, como fazem muitos, que elas tomam espontaneamente seu lugar no contexto da política de esquerda." (LACLAU; MOUFFE, 2015, p. 254).

Mas é justamente por isso que é preciso entender como se dá esse processo se quisermos tomar sua direção.

Isto significa em outras palavras que os projetos políticos que visam realizar o potencial democrático podem também paralisar e mesmo retroceder aos avanços da própria democracia. Os autores dão como exemplo do que estamos tentando mostrar a reorganização do espaço político no pós-guerra e a tentativa neoliberal de parar seus efeitos. Segundo eles, o pós-guerra levou e a criação de uma nova hegemonia política 
que por sua vez levou à mercantilização das relações sociais. Por um lado, este fato levou à expansão das formas de subordinação dos trabalhadores, antes subordinados apenas ao capital, agora também em todas as outras práticas sociais especialmente através da expansão dos veículos de comunicação em massa. Por outro lado, com essa nova forma de dominação assistiu-se também novas formas de resistência, como por exemplo, o movimento ecológico, movimentos urbanos, movimentos de minorias sexuais, de mulheres, de minorias étnicas entre outros.

Por trás deste conflito havia o Estado do Welfare State que crescentemente intervinha nas relações sociais através burocratização, absorvendo e neutralizando as crescentes demandas. A intervenção, por um lado, enfraqueceu alguns dos movimentos sociais em sua autonomia, mas por outro lado, levou à

[...] ampliação da noção de direitos, para incluir os chamados direitos coletivos ou sociais, [que] introduziu um fator de permanente disputa e mobilização, modificando profundamente o discurso liberal-democrático clássico. (BURITY, 1997).

No entanto, esses avanços sofreram um grande golpe com a contra-ofensiva que veio em seguida através do chamado neoliberalismo que levou ao desmantelamento do Welfare State e denuncia de um excesso de democracia. Mas o que é importante destacar é que a ascensão neoliberal só foi possível porque ao invés de colocar-se contra as novas formas de resistência ele as articulou em seu próprio discurso, logo em um discurso de direita.

Das duas primeiras sugestões decorre uma terceira. Se por um lado, devemos manter a pluralidade de espaços sociais e a diversidade das identidades, e por outro lado, articular a diversidade em torno de uma articulação hegemônica popular, isso significa que um projeto verdadeiramente radical e plural deve pautar-se na manutenção da tensão permanente entre autonomia e hegemonia, que representam cada um, os princípios democráticos da liberdade e da igualdade que são, em última análise, incompatíveis entre si, porém fundamentais. Por essa razão, deve basear-se na multiplicação dos espaços de lutas e, em seguida, promover a articulação dessas lutas em uma lógica hegemônica. Dessa forma, a democracia radical e plural visa

[...] promover o tipo de unificação dos movimentos democráticos que permita uma efetiva solidariedade sem pedir que nenhum movimento individual pague o preço da [...] cooptação e assimilação. Nenhum esforço deve ser autorizado a impor toda a sua agenda sobre outra. (SMITH, 1988, p. 32). 
Para Smith, é justamente essa combinação entre dois objetivos aparentemente contraditórios entre si, unidade e autonomia, a contribuição original de Laclau e Mouffe para a teoria democrática. A democracia radical e plural é, segundo ela, o "[...] tipo de estratégia política que pode alcançar a unidade e preservar a autonomia ao mesmo tempo, isto é, uma estratégia hegemônica plural democrática radical." (SMITH, 1988, p. 32). "A diferença deve ser celebrada como um bem positivo, mas apenas na medida em que não promova a dominação e desigualdade." (MOUFFE, 1992, p. 13 apud SMITH, 1988, p. 34). A diversidade

[...] deve ser afirmada como um bem em si mesmo; grupos minoritários nunca devem ser convidados a pagar o preço de auto-destruição cultural através da assimilação e neutralização disciplinar em troca de inclusão, legitimidade e reconhecimento. (SMITH, 1988, p. 33).

Daí a importância fundamental da multiplicação de espaços políticos e o impedimento de que o poder se concentre num só ponto. A tarefa para o pluralismo democrático radical é"[...] lutar contra o poder autocrático em todas as suas formas, a fim de se infiltrar nos diversos espaços ainda ocupados por centros de poder não democráticos."(MOUFFE, 1993, p. 94 apud SMITH, 1988, p. 34). Aqui a noção de antagonismo desempenha papel central, visto que sua função é justamente impedir "[...] qualquer possibilidade de uma reconciliação final, de qualquer tipo de consenso racional, de um 'nós' plenamente inclusivo." (LACLAU; MOUFFE, 2015, p. 46).

Uma quarta sugestão. A hegemonia criada através da articulação das diversas lutas em uma equivalência democrática deve construir um "[...]'senso comum' que modifique a identidade dos diferentes grupos, de tal maneira que as demandas de cada um sejam articuladas equivalencialmente com as dos outros." (LACLAU; MOUFFE, 2015, p. 272). É importante notar que a equivalência de demandas democráticas requerida pela lógica de uma democracia radical e plural não significa simplesmente que as lutas políticas dos diferentes grupos serão simplesmente aglutinadas. Não se trata de estabelecer uma "aliança de interesses", por que a equivalência modifica também as identidades das lutas do jogo. "Para que a defesa dos interesses dos trabalhadores não se faça às expensas dos direitos das mulheres, imigrantes ou consumidores, é necessário que se estabeleça uma equivalência entre essas diferentes lutas." (LACLAU; MOUFFE, 2015, p. 272). Logo, 
a equivalência não é simples aliança. Para que a equivalência seja verdadeiramente democrática, no sentindo de que ponha a funcionar não só a liberdade pela reivindicação de direitos realizada de forma individualista, mas também pela igualdade, um "algo em comum" precisa ser criado.

Isso quer dizer que o novo projeto positivo da esquerda também deve ter por missão a "[...] produção de um outro indivíduo, um indivíduo que não seja mais construído a partir da matriz do individualismo possessivo."(LACLAU; MOUFFE, 2015, p. 273). Ele deve ser diferente tanto daquele construído pelo liberalismo, quanto daquele construído pelo socialismo tradicional portador de uma identidade classista. Trata-se da construção de um sujeito democrático, ou em outras palavras, trata-se de construir um povo democrático, pois "[...] a possibilidade da democracia depende da constituição de um 'povo' democrático." (LACLAU, 2013, p. 248).

Quinta sugestão. Para que a esquerda possa construir um projeto político capaz de concorrer contra a hegemonia dominante é preciso que seu novo projeto político seja pautado em uma "estratégia de construção de uma nova ordem" e não em uma "estratégia de oposição". Isto porque segundo eles,

[...] se as demandas de um grupo subordinado são apresentadas como puramente negativas, subversivas de uma certa ordem, sem se vincularem a qualquer projeto viável de reconstrução de áreas específicas da sociedade, sua capacidade de agir hegemonicamente estará excluída, de saída. (LACLAU; MOUFFE, 2015, p. 279).

É preciso ao contrário, que o projeto da esquerda apresente-se como uma “[...] tentativa real de estabelecer diferentes pontos nodais a partir dos quais se poderia instituir um processo de reconstrução alternativa e positiva da textura social." (LACLAU; MOUFFE, 2015, p. 279).

Claramente no primeiro caso é o elemento da negatividade que predomina, enquanto no segundo, o elemento positivo é predominante. Isso não significa evidentemente que a dimensão contestatória estaria ausente do projeto da esquerda, mas apenas que "[...] este não pode consistir na afirmação, a partir de posições de marginalidade, de uma série de demandas anti-sistêmicas, [mas na] reconstrução positiva destas esferas, por parte dos grupos subordinados." (LACLAU; MOUFFE, 2015, p. 279). 
Por fim, uma última sugestão que podemos mencionar é que numa sociedade democrática radical deve haver igual acesso aos recursos materiais e também "[...] para a participação significativa na tomada de decisão nos campos social, cultural, político e econômico."(SMITH, 1988, p. 30). Dessa forma, embora não seja a parte mais fundamental do projeto de democracia radical e plural (já que não existe uma instância mais importante que outra), a dimensão da distribuição material é parte constitutiva deste. Esta é outra razão pela qual a contestação entre a linha que separa o público e o privado é tão importante, já que a hegemonia atual liberal advoga que a economia pertence ao âmbito privado, "[...] o berço dos direitos naturais, e que não há razões para se aplicar aí os critérios da democracia." (LACLAU; MOUFFE, 2015, p. 274). Para Laclau e Mouffe, ao contrário, não faz sentido no cenário atual, na era das corporações multinacionais, falar na economia como pertencente ao âmbito privado. Para eles o projeto de democracia radial e plural deve defender o direito à participação dos indivíduos na economia como produtores e não somente como cidadãos.

Obviamente, todo projeto de democracia radical implica numa dimensão socialista, pois é necessário por fim às relações capitalistas de produção, que estão na raiz de inúmeras relações de subordinação; mas o socialismo é um dos componentes de um projeto de democracia radical, e não vice-versa. Por isso mesmo, quando se fala da socialização dos meios de produção como um elemento da estratégia de uma democracia radical e plural, deve-se insistir que isto não pode significar apenas autogestão dos trabalhadores, pois o que está em jogo é a verdadeira participação de todos os sujeitos em decisões quanto ao que deve ser produzido, como se deve produzir, e às formas pelas quais o produto deve ser distribuído. (LACLAU; MOUFFE, 2015, p. 266).

Em suma, a democracia radical e plural é a fundação em cima do qual um projeto de esquerda deveria ser assentado. Ela não possui um caráter normativo forte, mas apenas direciona e sugere o caminho para onde a esquerda deveria seguir no intuito de articular um projeto democrático radical e plural para desafiar as estruturas vigentes. A ausência de normatividade é uma das principais críticas contra o projeto de Laclau e Mouffe, mas ela é propositiva. A normatividade limita e estatiza um projeto, que é o intuito oposto da democracia radical e plural, a qual busca adaptar-se à contingência do tempo e do espaço e deixar fluir a criatividade humana. 


\section{Considerações}

Neste artigo, tratamos da democracia radical e plural construída por Ernesto Laclau e Mouffe. Ela surge como uma série de sugestões para a esquerda política que, segundo os autores, deveria produzir um projeto político alternativo a atual ordem neoliberal e desafiar as instituições vigentes. O sucesso da empreitada dependeria, segundo eles, do reconhecimento adequado das relações nas sociedades atuais, muito mais contingentes e complexas do que aquelas pensadas pelo marxismo clássico.

A democracia radical e plural tem por objetivo central expandir os efeitos da Revolução Democrática e institucionalizar a irredutível tensão entre autonomia e hegemonia em favor de um equilíbrio político que deve ser constantemente renegociado. Ela visa à construção de um novo indivíduo diferente tanto daquele construído pelos liberais democratas quanto daquele criado pelo socialismo clássico. Um indivíduo democrático social.

\section{Referências}

BOBBIO, N.; MATTEUCCI, N.; PASQUINO, G. Dicionário de política. 11. ed. Brasília: Editora Universidade de Brasília, 1998.

BURITY, J. A. Desconstrução, hegemonia e democracia: o pós-marxismo de Ernesto Laclau. In: In: GUEDES, M. A. (Ed.). Política e contemporaneidade no Brasil. Recife: Bagaço, 1997.

FURET, F. Pensando a Revolução Francesa. Rio de Janeiro: Paz e Terra, 1989.

LACLAU, E. Nuevas reflexiones sobre la revolución de nuestro tiempo. Buenos Aires: Nueva Visión, 2000.

LACLAU, E. A Razão Populista. São Paulo: Três Estrelas, 2013.

LACLAU, E.; MOUFFE, C. Hegemonia e Estratégia Socialista: por uma política democrática radical. Rio de Janeiro: Intermeios, 2015.

MARQUES, L. Democracia radical e democracia participativa: contribuições teóricas à análise da democracia na educação. Education et Sociétés, v. 29, n. 102, p. 55-78, 2008.

MARX, K. Carta a Weidemeyer, 5/3/1846. In: MARX, K.; ENGELS, F. Obras escogidas de Marx y Engels. Madrid: Fundamentos, 1975. 2 v.

MOUFFE, C. The Return of the Political. London: Verso, 1993.

SMITH, A. M. The Radical Democratic Imaginary. London: Routledge, 1988. 
TAYLOR, C. A Política do Reconhecimento. In.:TAYLOR, C. (Ed.). Multiculturalismo. Lisboa: Instituto Piaget, 1998. p. 45-95.

TOCQUEVILLE, A. O Antigo Regime e a Revolução. 4. ed. Brasília: UNB, 1997.

Recebido: 23 ago., 2016

Aceito: 18 out., 2016 